\title{
O ENSINO DE VALORES COMO UMA POSSIBILIDADE NA REDUÇÃO DA INDISCIPLINA
}

\author{
Valéria Anésia Brumatti Jacon, Carmen Lúcia Dias \\ Universidade do Oeste Paulista - UNOESTE. Mestrado em Educação, Presidente Prudente - SP. E-mail: \\ vabrumatti@hotmail.com
}

\section{RESUMO}

O tema indisciplina em sala de aula tem sido palco constante para discussões e pesquisas na área da educação, se destacando como um dos motivos que tem levado a problemas de ensino e de aprendizagem, visto que este tipo de comportamento prejudica o trabalho do professor, além de causar diversos problemas nas relações interpessoais dentro do contexto escolar. O presente artigo apresenta uma sistematização teórica sobre a indisciplina escolar e suas principais causas; a moralidade e a construção de valores a partir da contribuição de pesquisadores referência na área. Conclui-se que o Ensino de Valores pode possibilitar a redução da indisciplina e, aos alunos, a construírem e a exercitarem a autonomia, respeitando o próximo e assim formando cidadãos éticos e preparados para viver em sociedade.

Palavras-chave: Indisciplina. Ensino de Valores. Contexto Escolar. Autonomia.

\section{THE VALUES TEACHING HOW A POSSIBILITY IN THE INDISCIPLINE REDUCTION}

\begin{abstract}
The theme of indiscipline in classroom has been constant stage for discussions and researches in education area, it's detaching how one of the reasons that has taken to teaching and learning problems, seen that this kind of behavior damages the teacher's work, besides causing several problems in the interpersonal relations in the scholar context. The present article presents a theoretical systematization about the scholar indiscipline and its main causes; the morality and the values construction from the contribution of reference researchers in the area. It follows that the Values Teaching may enable the indiscipline reduction and, to students, build and exercise the autonomy, respecting the next and thus forming ethical and prepared citizens to live in society.
\end{abstract}

Keywords: Indiscipline. Values Teaching. Scholar Context. Autonomy. 


\section{INTRODUÇÃO}

O tema indisciplina em sala de aula tem sido palco constante para discussões e pesquisas na área da educação, se destacando como um dos motivos que tem levado a problemas de ensino e de aprendizagem, visto que este tipo de comportamento prejudica o trabalho do professor, além de causar diversos problemas nas relações interpessoais dentro do contexto escolar.

Para que seja possível uma aprendizagem qualificada, o ambiente escolar, principalmente a sala de aula deveria ser um local motivador, fazendo com que o aluno pudesse aprender de maneira prazerosa. A indisciplina constantemente presente no contexto educacional tem contribuído para o baixo rendimento escolar.

O uso de técnicas e instrumentos, tais como, vídeos, músicas, atividades lúdicas, recursos tecnológicos e muitos outros, que proporcionem um melhor aproveitamento no âmbito escolar é fator importante e determinante para se conseguir realizar um trabalho de forma eficaz, porém infelizmente mesmo quando essas técnicas e instrumentos são utilizados, na maioria das vezes o professor não consegue alcançar o objetivo almejado devido à indisciplina de alguns alunos.

Outro aspecto fundamental e que tem contribuído para o aumento de tal situação é a falta que alguns valores morais essenciais para uma boa convivência têm ocasionado, valores como, respeito, cooperação, justiça, solidariedade, diálogo, entre muitos outros.

Portanto, é necessário buscar meios que melhorem o ambiente escolar visando uma melhor aprendizagem e para isso tentar encontrar a origem do problema certamente contribuirá para que esta melhora aconteça.

Atendendo a esta preocupação, o presente artigo, apresenta uma sistematização teórica sobre a indisciplina escolar e suas principais causas; a moralidade e a construção de valores a partir da contribuição de pesquisadores referência na área.

\section{INDISCIPLINA}

Segundo o Dicionário Escolar da Língua Portuguesa, indisciplina é desobediência; desordem; rebelião" (Bueno, 1986, p.598) e disciplina é "ordem; respeito, obediência às leis" (p.374). Portanto, segundo o dicionário, ser indisciplinado significa não obedecer ao conjunto de regras que têm por objetivo manter a boa ordem em uma organização (a escola, por exemplo), não obedecer à autoridade e ser rebelde.

Zechi (2008), pesquisou sobre a violência e indisciplina em meio escolar por meio de um levantamento bibliográfico de estudos produzidos em Programas de Pós-graduação em Educação do Estado de São Paulo de 2000 a 2005, constatando que: 
A manutenção da disciplina no contexto escolar constitui uma preocupação de todas as épocas. O que vem ocorrendo nos últimos anos é que a violência e indisciplina escolar se tornaram explícitas e, freqüentemente, a literatura - tais como livros, pesquisas científicas, jornais, revistas e até mesmo noticiários - tem ilustrado esses fatos. (ZECHI, 2008, p.11).

Para Aquino (1996), no contexto educativo, um aluno indisciplinado é visto não como aquele que questiona e se movimenta o tempo todo, mas sim como aquele que não respeita os outros, não tem limites para suas atitudes, encontra dificuldade em entender o próximo, dialogar, conviver cooperativamente e de se autocontrolar.

Ainda do autor,

Há muito os distúrbios disciplinares deixaram de ser um evento esporádico e particular no cotidiano das escolas para se tornarem, talvez, um dos maiores obstáculos pedagógicos dos dias atuais. Claro está que, salvo o enfrentamento isolado e personalizado de alguns, a maioria dos educadores não sabe ao certo como interpretar e/ou administrar o ato indisciplinado. Compreender ou reprimir? Encaminhar ou ignorar? (AQUINO, 1996, p. 7).

Portanto, a indisciplina vem sendo vista como uma atitude de desrespeito, de intolerância ao acordo firmado do não cumprimento de regras capazes de pautar a conduta de um indivíduo ou de um grupo, é considerada também um reflexo da indisciplina generalizada em que se encontra a humanidade atualmente. Essa por sua vez vem crescendo constantemente, é o resultado de uma sociedade onde não existe mais o respeito, o amor, a compreensão e o valor família. Cada vez é mais difícil estabelecer a disciplina e fazê-la respeitar. Com as evoluções da vida em todos os sentidos, as crianças se tornaram mais independentes e passaram a obedecer menos a autoridade dos adultos.

A respeito da definição do termo indisciplina La Taille coloca:

Definir indisciplina não é tarefa fácil. Ao contrário. O tema é delicado, perigoso até. Segundo o autor, são três os motivos que justificam essa afirmação: - dizer que a indisciplina acontece pela falta de valores do nosso tempo pode ser um moralismo ingênuo; - explicar o fenômeno em uma única dimensão excluiria outras perspectivas, como sociológicas e pedagógicas; - a indisciplina pode ter muitas interpretações dependendo do contexto onde está inserida, trazendo consigo uma certa ambigüidade. (LA TAILLE, 1996, p.9).

Neste contexto Rego conceitua a indisciplina:

[...] o conceito de indisciplina, como toda criação cultural, não é estático, uniforme, nem tampouco universal. Ele se relaciona com o conjunto de valores e expectativas que variam ao longo da história, entre as diferentes culturas e numa 
mesma sociedade: nas diversas classes sociais, nas diferentes instituições e até mesmo dentro de uma mesma camada social ou organismo (REGO, 1996, p.84).

Com isso, verificamos que a indisciplina é um comportamento cuja origem pode ser difícil de ser detectada, até porque pode surgir por diversos motivos, os quais devem ser analisados criteriosamente para não cometer nenhum julgamento incorreto. Vivemos em um mundo com mudanças constantes e no qual estão inseridas diversas culturas, portanto precisamos perceber que o sentido de indisciplina, também pode estar se modificando de acordo com os valores existentes entre culturas diferentes e até mesmo dentro de uma mesma cultura.

Uma forma muito marcante de expressão da indisciplina é através de comportamentos considerados inadequados para o ambiente escolar, como também para o bom convívio em sociedade, os quais mostram rebeldia, intransigência, bagunça ou agitação, desacato, transmitidos através da falta de educação ou de respeito pelas autoridades escolares.

É nesse momento que percebe-se a falta que alguns valores morais ${ }^{1}$ fazem para um convívio em harmonia dentro do ambiente escolar, como também para a vida em sociedade.

Segundo Menin a Educação em Valores é

Aquela que tem por finalidade a transmissão, construção e prática de princípios, valores, normas e regras que orientem as pessoas a viverem o mais harmonicamente possível consigo mesmas e com os demais e dentro do que normalmente se considera na cultura como justo, bom, correto. (MENIN, 2013, p. 23-24).

A indisciplina pode ter sua origem em diversos fatores, portanto difícil de ser interpretada e julgada.

De acordo com Rego:

A família, entendida como o primeiro contexto de socialização, exerce, indubitavelmente, grande influência sobre a criança e o adolescente. A atitude dos pais e suas práticas de criação e educação são aspectos que interferem no desenvolvimento individual e, consequentemente, influenciam 0 comportamento da criança na escola (REGO, 1996, p.97).

Assim, Trevisol (2009), diz que precisa-se considerar que a família é a base para a vida social, pois é dentro desse contexto que os indivíduos iniciam suas interações com a sociedade e com as regras que a regem. Porém, quando o indivíduo não adquire essa base moral durante toda sua infância, este chegará à escola sem possuir os princípios que a orienta, então, tanto o ambiente

\footnotetext{
${ }^{1}$ De acordo com Piaget (1994, p. 23), "toda moral consiste num sistema de regras e a essência de toda moralidade deve ser procurada no respeito que o indivíduo adquire por estas regras".
} 
escolar, como as pessoas que dele fazem parte serão vistos como algo de pouco valor ou de pouco significado, fazendo com que esses indivíduos não tenham cuidado nem com o ambiente escolar, nem com os membros que dele fazem parte.

Outro fator que deve ser levado em consideração é o contexto social em que a criança está inserida, o qual exerce grande influencia em seu comportamento, até porque se esse meio fornecer a ela elementos fundamentais para sua formação moral, certamente esta criança não apresentará tantos problemas disciplinares como àquela que, em seu contexto social foi exposta a situações de violência, sem base cultural adequada à sua formação, fazendo com que a mesma reproduza através de ações indisciplinadas todo o reflexo da sua formação.

Também não podemos nos esquecer do ambiente escolar em que a criança está inserida, pois se este for um local no qual prevalece o autoritarismo, provavelmente a indisciplina será crescente. Para tanto, é necessário que a escola seja um contexto em que o diálogo aconteça com frequência, em todas as situações, promovendo a participação dos alunos e fazendo com que esses sintam-se realmente parte desse meio. Mas, o que fazer?

\section{A IMPORTÂNCIA DAS REGRAS, DO SABER OUVIR E DO ENSINO DE VALORES}

Devemos ressaltar que a escola precisa de regras e normas capazes de orientar para que seu funcionamento e a convivência dos que nela atuam aconteça com qualidade e eficiência. Essas regras devem ser compreendidas como condição essencial para o convívio social, sabendo que a obediência a certas regras, ao contrário do que muitos possam pensar, pode fazer com que o indivíduo consiga desempenhar uma atitude autônoma e consequentemente libertadora, já que oferecem orientações entre as relações sociais. Neste contexto o responsável pela transferência dessas regras passa a ser o educador, o qual educa, oferece parâmetros e determina limites (REGO, 1996).

Ainda, de acordo com Carvalho:

o trabalho do professor não é o de fixar, através de certas receitas, comportamentos invariáveis, mas o de criar, segundo seus objetivos e as características daquilo que ensina, disciplinas e métodos de ação e pensamento que consideramos valiosos. Ter um método para transmitir disciplinas não é ter um discurso sobre a disciplina, mas é criar uma maneira de trabalhar! Tal maneira será tanto mais eficaz quanto mais o professor tiver clareza de objetivos e procedimentos dos conteúdos ou áreas de conhecimento com os quais deseja trabalhar. Nesse sentido, o problema da disciplina escolar desloca-se do âmbito e da perspectiva moral e comportamental para situar-se no âmbito da apropriação de práticas e linguagens públicas, em cuja difusão reside a principal atividade das instituições escolares. (CARVALHO, 1996, p. 138). 
Segundo Puig (1998, p.234) "o momento, a preparação, o tom de voz, o respeito e muitos outros detalhes acabam sendo a arte pedagógica que faz tanto da neutralidade como da beligerância um instrumento formativo útil para os aprendizes."

Uma outra possibilidade é a realização de uma análise na origem do problema, a partir daí que se conhece os motivos que levam os indivíduos a se comportarem de forma indisciplinada. Observar os alunos e estabelecer um diálogo também pode ajudar muito.

Do ponto de vista de Vasconcellos (1994, p.50) "é preciso saber ouvir e compreender a mensagem que se esconde por trás do comportamento manifesto como indisciplina".

Isso nos faz refletir sobre a importância da educação moral e a participação fundamental que a escola tem nisso, pois é no ambiente escolar, através dos professores, material didático, projetos interdisciplinares e transdisciplinares desenvolvidos pela organização institucional que valores e regras são transmitidos.

Daí então a importância da realização de uma educação moral que não apenas transmita valores fundamentais para a vida em sociedade, como também proporcione aos alunos condições para o desenvolvimento de sua autonomia, fazendo com que sejam capazes de se posicionar e até mesmo atuar em situação de conflito.

De acordo com Moreno

Os valores morais nos permitem encontrar sentido no que fazemos, responsabilizar-nos por nossas ações, tomar decisões com serenidade e coerência, resolver os conflitos pessoais, familiares ou de relações interpessoais com uma certa garantia de sensatez e de elegância espiritual e humana. (MORENO, 2005, p. 132).

Ainda de acordo com o autor, "a educação deve permitir o exercício dos valores que tornam possível a vida em sociedade, especialmente o respeito aos direitos e às liberdades fundamentais e a aquisição de hábitos de convivência e de respeito mútuo." (MORENO, 2005, p. 133).

Verifica-se, portanto, o quanto a escola precisa empenhar-se em desenvolver nos alunos uma formação moral e ética, sendo que através dela é que poderemos construir um mundo melhor e mais pacífico, no entanto, para que isso aconteça é necessário refletir a respeito dos princípios que fundamentam os valores na construção da cidadania na escola.

Para os nossos Parâmetros Curriculares Nacionais (BRASIL,1998) aprender sobre moral, é aprender a fazer, é aprender a viver cooperativamente, de forma justa e respeitosa.

Segundo Lepre 
a educação moral deve contribuir para a aquisição de critérios que guiem, regulem e proporcionem normas orientadoras para a vida prática das pessoas e da coletividade, tais como a crítica, o princípio de alteridade, a Declaração Universal dos Direitos Humanos, a implicação e compromisso. (LEPRE, 2005, p. 9).

Para Puig

Do ponto de vista pedagógico, a clarificação de valores baseia-se na ação consciente e sistemática do educador, que tem por objetivo estimular processos de valorização que levem os alunos à compreensão de quais são os seus valores, para que possam sentir-se responsáveis e comprometidos com os mesmos. Para estimular esse processo, o educador deve proporcionar programas e experiências que favoreçam o autoconhecimento consciente quanto aos valores preferidos, evitando toda doutrinação ou inculcação. (PUIG, 1998, p.39).

Dessa forma, uma educação fundamentada no ensino de valores morais e éticos pode ganhar seu sentido mais nobre e verdadeiro na prática do ensino. Se a educação básica é para a vida, a quantidade e a qualidade do conhecimento têm de ser determinadas por sua relevância para a vida de hoje e do futuro, para além dos limites da escola. Portanto, mais do que os conteúdos isolados, os conhecimentos e práticas de valores morais e éticos são guias eficazes para educar para a vida.

\section{CONSIDERAÇÕES FINAIS}

Destas reflexões, depreende-se a importância de se refletir sobre o ensino de valores morais e éticos que configuram uma educação de melhor qualidade e mais completa, voltada ao desenvolvimento da autonomia, refere-se às múltiplas capacidades do indivíduo em se representar tanto nos espaços públicos como nos espaços privados da vida cotidiana, ao seu modo de viver e aos seus valores culturais: à forma de ser, sentir e agir; à resolução de conflitos; ao fortalecimento em relação às suas próprias emoções, que o torna capaz de se solidarizar com as emoções dos outros e, enfim, estar mais associados em suas ações. Assim, um dos caminhos para a concretização dessas ações é trabalhar por meio de um ensino pautado nos valores morais e éticos essenciais para a vida em sociedade, cabendo isso a cada educador em sua sala de aula com seus alunos.

Sabemos que todo indivíduo, em especial nossos alunos, necessitam de bases morais bem definidas, para que assim possam estar preparados para agir diante dos pequenos e grandes problemas, sabendo questionar quando preciso e atuar de forma autônoma nas tomadas de decisões. 
Para isso, o papel do educador e da escola no processo de transmissão de valores para seus alunos é de extrema importância, pois seus exemplos serão norteadores para suas vidas, contribuindo para a construção da cidadania.

Portanto, podemos verificar a importância de uma educação baseada em valores essenciais para o convívio social e a possibilidade de redução da indisciplina. Desta forma, estaremos convidando nossos alunos a acreditarem, construírem e a exercitarem tais valores, respeitando o próximo e assim formando cidadãos éticos e preparados para viver em sociedade.

\section{REFERÊNCIAS}

AQUINO, J. G. Indisciplina na escola - alternativas teóricas e práticas. 4 ed. São Paulo: Summus, 1996.

BRASIL, Secretaria de Educação Fundamental. Parâmetros Curriculares Nacionais; terceiro e quarto ciclo: apresentação dos temas transversais. Brasília: MEC/SEF, 1998.

BUENO, F. da S. Dicionário escolar da Língua Portuguesa; Ministério da Educação: Fundação de Assistência ao Estudante. 11 ed. Rio de Janeiro, 1986.

CARVALHO, J. S F. de. Os sentidos da (in)disciplina: regras e métodos como práticas sociais. In: AQUINO, J. G. Indisciplina na escola - alternativas teóricas e práticas. 4 ed. São Paulo: Summus, 1996. p. 129-138.

LA TAILLE, Y. de. A indisciplina e o sentimento de vergonha. In: AQUINO, J. G. (Org). Indisciplina na escola: alternativas teóricas e práticas. 4. ed. São Paulo: Summus, 1996. p. 9-23.

LEPRE, R. M. Educação moral na escola: caminhos para a construção da cidadania. Colloquium Humanarum, 2005, v.3(1), p.01-12.

MENIN, M. S. de S.; BATAGLIA, P. U. R.; ZECHI, J. A. M. Projetos bem-sucedidos de educação em valores: relatos de escolas públicas brasileiras. São Paulo: Editora Cortez, 2013. p. 21-26.

MORENO, C. I. Educar em valores. 3 ed. São Paulo: Editora Paulinas, 2005.

PIAGET, J. O juízo moral na criança. São Paulo: Summus, 1994.

PUIG, J. M. A construção da personalidade moral. São Paulo: Editora Ática, 1998.

REGO, T. C. R. A indisciplina e o processo educativo: uma análise na perspectiva Vygotskiana. In: AQUINO, J. G. (Org). Indisciplina na escola: alternativas teóricas e práticas. 4 ed. São Paulo: Summus, 1996. p. 83-101.

TREVISOL, M. T. C. Tecendo os sentidos atribuídos por professores do ensino fundamental ao médio profissionalizante sobre a construção de valores na escola. In: LA TAILLE, Y. de. MENIN, M. S. de S. e Cols. Crise de valores ou valores em crise? São Paulo: Artmed, 2009. p. 152-184. 
VASCONCELOS, C. dos S. Disciplina: construção da disciplina consciente e interativa em sala de aula e na escola. São Paulo: Libertad, 1994.

ZECHI, J. A. M. Violência e Indisciplina em meio escolar: aspectos teórico-metodológicos da produção acadêmica no período de 2000 a 2005. 2008. Dissertação (Mestrado em Educação) Universidade Estadual Paulista, Faculdade de Ciências e Tecnologias, Presidente Prudente. 